\title{
Implementing CDIO Approach in preparing engineers for Space Industry
}

\author{
Yury Daneykin ${ }^{1,}$, , Natalia Daneikina ${ }^{1}$, Michail Solovyov ${ }^{1}$ and Arun Patil ${ }^{2}$ \\ ${ }^{1}$ Tomsk Polytechnic University, 634050 Tomsk, Russia \\ ${ }^{2}$ Deakin University, Australia
}

\begin{abstract}
The necessity to train highly qualified specialists leads to the development of the trajectory that can allow training specialists for the space industry. Several steps have been undertaken to reach this purpose. First, the University founded the Space Instrument Design Center that promotes a wide range of initiatives in the sphere of educating specialists, retraining specialists, carrying out research and collaborating with profiled enterprises. The University introduced Elite Engineering Education system to attract talented specialist and help them to follow individual trajectory to train unique specialist. The paper discusses the targets necessary for achievement to train specialists. Moreover, the paper presents the compliance of the attempts with the CDIO Approach, which is widely used in leading universities to improve engineering programs.
\end{abstract}

\section{Introduction}

Tomsk Polytechnic University aims at training highly qualified specialists in various technical areas. One of the quite modern area is space industry that needs professional solutions and experts. Therefore, there is an acute necessity to find ways to improve the quality of educational programs and training of specialists.

In 2011 Tomsk Polytechnic University joined CDIO Initiative - the major international project on the reform of engineering education, which began in October 2000 at the Massachusetts Institute of Technology (MIT, USA) with the participation of scientists, teachers and industry representatives [1]. The intention was to improve the quality of education constantly using all the tools possible. The CDIO approach to engineering programs modernization provides the innovative framework for producing the new generation of engineers. Implementation of the CDIO approach in practice requires significant changes in program development, realization and assessment. To design and implement new programs the university faculty have to improve their competences in curriculum development in compliance with the CDIO Syllabus, in integrated learning experiences, in active and experiential learning, and assessing student learning [2]. Authors believe that implementing CDIO Approach will highly increase the quality of education. Particularly, the improvements are necessary in aerospace industry, as the technologies used in this industry have been developing rapidly and specialists with particular train ing are on demand.

* Corresponding author: daneykin@tpu.ru 


\section{Training of specialists in space industry}

Tomsk Polytechnic University has Space Instrument Design Center whose aim is contributing to the improvement of specialists' training and research in the sphere of space industry. It states the following purposes [3]:

- Advanced training of world-class experts in the field of Space Device Engineering (masters and $\mathrm{PhDs}$ ).

- Carrying out research, development work in the field of design, engineering, production and testing of space technology and ground-based equipment in tight connection with the enterprises.

- Implementation of the results of joint innovative research and educational activities

- Development of various forms of post-graduate education, including vocational training and skills development in the field of new space technology and ground-based equipment

In addition, the Center complete the following tasks:

- Providing targeted training for enterprises on the agreed individual educational trajectory.

- Preparation of training and methodological support for implementation of the Master's programs developed by request and with the participation of enterprises.

- Organization of educational and production practices for students that contribute to the maximum approximation to the real conditions of production and research activities

- The formation and consolidation of practical skills of future specialists and practical skills obtained through theoretical training, including by working in multidisciplinary teams.

- Carrying out research activities in the interest of enterprises.

- Promote the establishment of joint enterprises and innovative structures, the establishment of joint educational and research laboratories.

- Implementation of joint cross-disciplinary research and development work and innovative projects with the involvement of the bachelors, masters and $\mathrm{PhD}$ students .

\section{Targets to achieve}

Aerospace is the industry of cutting-edge technologies. The highly integrated yet interdisciplinary nature of aerospace manufacturing requires graduates with a broad knowledge of technologies, professional skills, and a system-level mind set [4] [5]. The purpose of the authority of the university is the modernization of the basic engineering education provision of training graduates for complex engineering activity.

The faculty states the following targets to achieve a high level of training.

1. Preparedness to complex engineering activity, which includes the readiness of enterprises to take part in the organization of students' project work (themes of the projects, expendable materials, supervisors) and efficiency of the realization of project activities in the departments.

2. Practical part of training. This includes the readiness of enterpris es to take students for traineeship (providing them with actual themes, supervision), terms and practical content of traineeship, efficiency of traineeship organization.

3. Elite Engineering Education (EEE) system provides the new structure of program. For the last year, the number of the students involved increased that confirms the popularity of the format. The formation of education track ("Innovations", "Research", and "Technology") is individual that also attracts the potential participants. 
4. Set of measures on interaction with enterprises, which includes the readiness of enterprises to participate in the life of university. It will influence the efficiency of realization of this work in university (monitoring, taking management decisions).

5. Targeted training means the readiness of enterprises to sign contracts with senior students on targeted education, possible social support, organization and monitoring of this work in university.

6. Development of universal competences demanded by employers, taking into account the opinion of enterprises about the universal competences (Federal State Education Standard, additional competences), necessity to know English.

The main objective is to develop students' interest to engineering, strengthen motivation to learning in accordance with the selected direction or specialty, as well as to provide the basis for the development of practical skills.

\section{Elite engineering education system}

Elite Engineering Education system was introduced at TPU in 2004 on the basis of specialists' and undergraduates' educational programs. In 2014 it was first introduced for Master's degree students. The purpose of EEE system is training of the future leaders of the engineering profession for innovation and entrepreneurship. EEE program is a program of additional training. Learning outcomes include profound knowledge of fundamental sciences (Mathematics, Physics, Economics), competences in the sphere of engineering entrepreneurship, leadership qualities and teamwork skills, holistic worldwide vision and formation of axiological complex thinking.

\section{Interaction with enterprises}

As we mentioned above close interaction with enterprises. They are involved in a number of activities helping to understand the demands of the market, need in technologies, direction for the improvement of educational programs, ways to organize learning environment and practical training, assess the competitiveness of educational program, the set of competences necessary for the graduates. So areas of interaction with enterprises include as follows.

Design of General educational program (GEP)

- Participation in the design of content of educational modules

- Evaluation of resources for realization of educational program (equipment, site, software etc.)

Realization of GEP

- Open lectures with participation of representatives of enterprises

- Representation of professional modules of GEP (formation of professional and universal competences), e.g. for acquiring blue-collar jobs

- Discussion of the themes of final assignments

- Organization of training experience

- Supervision of final assignments

- Traineeship of teachers

Assessment of the quality of GEP

- Assessment of students' competences (traineeship, course assignments, final assignments)

- Assessment of final assignments (participation in state examination commission) 
The improved educational programs provide the achievement of all these competences. Moreover, TPU is now working to rethink educational programs based on CDIO Syllabus, which will enable the creation of a modern level of educational standards

\section{Compliance with CDIO Standards}

Let us look at the compliance of the targeted educational program with the CDIO Standards. Mostly we were concerned with the Standards 2, 3 and 8.

Standard 2 underlines the importance of engineering reasoning and problem solving, experimentation and knowledge discovery, system thinking, creative thinking, critical thinking, and professional ethics. Interpersonal learning outcomes include teamwork, leadership, communication, and communication in foreign languages, conceiving, designing in enterprise etc. Standard 3 says about reaching the targeted learning outcomes in disciplinary knowledge and skills, where faculty play an active role in designing the integrated curriculum by suggesting appropriate disciplinary linkages, as well as opportunities to address specific skills in their respective teaching areas. Therefore, we success fully used content-based instruction, learning professional skills through tight work with enterprises and the system of elite educational training with individual trajectory of study. Standard 8 suggests using methods of active learning, which were applied when realizing the real team projects, which were developed both in laboratories and in enterprises after discussion with experts.

\section{Conclusions}

Space industry needs specialists with both broad and deep knowledge, professional competences and personal skills. Special Space Instrument Design Center founded in TPU sets a number of tasks that highly contribute to the development of science for further implementation in the industry, including doing research by the order of enterprises.

Special Elite Engineering Education system contributes to the formation of a specialist with specific skills, developed with the view of future work.

In addition, the authors believe that CDIO Approach, which has been widely used recently to improve and develop engineering programs, can contribute to the improvement of Engineering programs aimed at the training of highly-qualified specialists in the area. The comprehensiveness of Approach make it a good tool that can be implemented in engineering programs in various aspects.

\section{References}

1. E. Crawly, J. Malmqvist, Rethinking Engineering Education (Springer Science and Business Media, 2007)

2. A. Kriushova, et al, INTED Proc. (2016)

3. TPU official site, URL http://portal.tpu.ru/departments/centre/noc kp

4. Ir. Aldert Kamp, Proc. of the 8th Int. CDIO Conf. (2012)

5. Yu. Daneykin, E. Serebryakova, M. Solovjev, I. Abrashkina, Nauka i obrazovanie, 7, 336 (2016) 